\title{
O ensino de literatura nas aulas de ELE: proposta de aplicação da literatura comparada e das TIC
}

\author{
Amanda Maria Elsner Matheus ${ }^{i}$ \\ Leila Shaí Del Pozo González ${ }^{\text {ii }}$ \\ Danielle Josiane Winkert ${ }^{\mathrm{iii}}$
}

\section{RESUMO}

A ausência de matérias específicas de literatura na escola pública ainda promove o estigma de a Literatura ocupar o espaço de "assuntos mais urgentes". Abordar a Literatura tem sido um desafio para os professores, sobretudo quando se pensa na possibilidade de seu ensino nas aulas de Espanhol como Língua Estrangeira (ELE). Desse modo, este artigo tem como objetivo propor atividades de uso da Literatura nas aulas de ELE, criadas com o auxílio das TIC, ou selecionadas da internet, sob a premissa metodológica da formação do leitor literário, mediadas pelo professor leitor, e da Literatura Comparada, com o intuito de desmistificar a impossibilidade de ensinar literatura nas aulas de língua nas atividades de ensino remoto emergencial.

Palavras-chave: Ensino-aprendizagem de Literatura nas aulas de ELE; Formação do leitor literário; Uso de TIC nas aulas de língua estrangeira.

\section{RESUMEN}

\footnotetext{
${ }^{\text {i }}$ Mestranda em Letras, na área de Linguagem Literária e Interfaces Sociais: Estudos Comparados pela Universidade Estadual do Oeste do Paraná (2019-2021). Pós-Graduada em História e Cultura Brasileira e Africana, Gestão Escolar e Educação Especial Inclusiva, pela Faculdade de Educação e Tecnologia da Região Missioneira - FETREMIS. Graduada em Letras Português/Espanhol pela Universidade Estadual do Oeste do Paraná (2009). | https://orcid.org/0000-0001-8534-8505 | amandamaria.elsner@ gmail.com

ii Doutoranda em Letras pelo Programa de Pós-Graduação Stricto Sensu. Bolsista do Programa de demanda social - CAPES. Mestre em Letras pela UNIOESTE (2017). Graduada em Letras (Português/Espanhol) (2014) e em Letras (Português/Inglês) (2018) pela UNIOESTE. Docente na Universidade Estadual do Oeste do Paraná. | https://orcid.org/0000-0002-2654-0414 | leilashai@hotmail.com

iii Estudante de graduação no curso de Letras, com habilitação em espanhol e suas respectivas literaturas na Universidade Estadual do Oeste do Paraná. Formou parte do projeto de iniciação científica "O ensino da literatura nas aulas de línguas estrangeiras aliado ao uso das Tecnologias de Informação e Comunicação", como bolsista, 2018-2019. Atua no projeto de IC voluntária "Ressignificações da Guerra do Contestado na Literatura". | https://orcid.org/0000-0002-9856-4562 | winkertdani@ hotmail.com
} 
La ausencia de materias específicas de literatura en la escuela pública todavía promueve el estigma de la Literatura ocupar el espacio de "asuntos de más urgencia". Abordar la Literatura ha sido un desafío para los profesores, sobre todo cuando se piensa en la posibilidad de su enseñanza en las clases de español como Lengua Extranjera (ELE). De ese modo, este artículo tiene como objetivo proponer actividades de uso de la Literatura en la enseñanza de las clases de ELE, creadas con el auxilio de las TIC, o seleccionadas de la internet, bajo la premisa metodológica de la formación del lector literario, mediada por el profesor lector, y de la Literatura Comparada, con el objetivo de desmitificar la imposibilidad de impartir literatura en las clases de lengua en las actividades de enseñanza remota de emergencia.

Palabras clave: Enseñanza-aprendizaje de Literatura en las clases de ELE; Formación del lector literario; Uso de TIC en las clases de lengua extranjera.

\section{INTRODUÇÃO}

O ano escolar em 2020 tem sido afetado pela pandemia do novo 'coronavírus'. No contexto de aula na escola pública brasileira, a tentativa de traduzir uma aula normal ao ensino a distância, nas primeiras semanas, apontou para diversos aspectos com os quais muitos professores foram confrontados, dentre estes, a falta de preparação, de prática de uso e/ou desconhecimento das tecnologias de informação e digitais.

Partindo disso, percebemos que uma reflexão mais realista nos leva a reconhecer que a escola pública brasileira não se encontra dentro do contexto da Educação a Distância - EaD, e sim, por causa da pandemia, dentro de um contexto de ensino remoto emergencial. Vimos na prática a dificuldade inicial na metodologia aplicada para o preparo das aulas. A educação, nesse momento, exige uma abordagem diferente que leve em conta o componente tecnológico, elemento que não pode ser ignorado.

Em contrapartida, para ensinar literatura, faz-se necessário sair de nosso lugar de conforto, motivo pelo qual há uma atitude de rejeição da Literatura em sala de aula, verificável não apenas do ponto de vista dos aprendizes, mas dos próprios professores. A leitura literária é uma experiência da qual nem todos desfrutam. Contudo, é preciso ir além, caso nosso objetivo seja preparar, de modo efetivo, os estudantes de língua estrangeira.

Nesse sentido, no presente estudo, pretendemos aportar com alguns materiais por nós elaborados, ou selecionados da internet, para auxiliar o professor de ELE, aquele que, em meio aos últimos acontecimentos, fazendo todos os esforços, utiliza a 
internet para continuar a dar aulas e, desse modo, incentivá-lo a usar a literatura nas suas aulas.

Propomos fazer uso da Literatura nas aulas de ELE, sob a perspectiva da Literatura Comparada, com o auxílio das Tecnologias da Informação e Comunicação TIC, de modo a oportunizar discussões no que tange à formação do leitor literário crítico. Além dos materiais TIC, oferecemos na seção denominada "Propostas" uma sugestão de uso da Literatura Comparada que conversa com o texto da picaresca espanhola El Lazarillo de Tormes (1554), de autor anônimo, de forma a propor um retorno dos alunos sobre sua leitura da obra.

Nessa perspectiva, abordamos a seguir alguns aspectos teóricos a respeito da importância da literatura nas aulas de línguas estrangeiras, bem como a utilização de recursos tecnológicos no ensino-aprendizagem.

\section{APORTES TEÓRICOS}

Incluir o ensino de Literatura nas aulas de língua estrangeira é proporcionar o direito à Literatura (Cf. CANDIDO, 2004). Ensinar língua não se trata simplesmente de ampliar o léxico e o conhecimento de mundo dos alunos, mas também de despertar neles a atitude reflexiva sobre si e sobre o mundo. No capítulo 2, Conhecimentos de Literatura, as Orientações Curriculares Nacionais - OCN discutem que:

\footnotetext{
O discurso literário decorre, diferentemente dos outros, de um modo de construção que vai além das elaborações linguísticas usuais, porque de todos os modos discursivos é o menos pragmático, o que menos visa a aplicações práticas. Uma de suas marcas é sua condição limítrofe, que outros denominam transgressão, que garante ao participante do jogo da leitura literária o exercício da liberdade, e que pode levar a limites extremos as possibilidades da língua. (BRASIL, 2006, p. 49)
}

Segundo Osakabe (apud. BRASIL, 2006, p. 49) a função maior da literatura estaria em ser o fator agenciador do amadurecimento sensível do aluno, proporcionando-lhe o exercício da liberdade, tendo como resultado seu desenvolvimento crítico e fazendo dele uma pessoa menos preconceituosa diante do mundo. As OCN se posicionam a favor da permanência da Literatura no currículo do ensino médio e lembram que a Literatura já teve seu próprio espaço dentro dos tidos 
como essenciais para o ensino. Alega que a Literatura humaniza o homem coisificado, rompe com a hegemonia do trabalho alienado no mundo dominado pela mercadoria.

Seguindo este pensamento, quando se trata de ensinar um idioma a um aluno, este fica exposto a uma cultura nova e, nesse sentido, os textos literários são de grande importância, visto que "Língua e Literatura se inter-relacionam e se explicam mutuamente. Por isso, devem combinar-se para oferecer ao estudante estrangeiro uma visão mais completa da língua e da cultura que quer conhecer" (SANTAMARÍA, 2000, p. 653 - tradução nossa). Embora a realidade mostre que, em geral, no ensino de idiomas, o conhecimento e a compreensão da literatura não tenham sido objetivos predominantes, é fundamental entender que a leitura literária contribui para uma formação humanizadora.

Com respeito ao uso das teorias da Literatura Comparada, Pereira (2015, p. 8083) menciona que quando se trabalha fazendo uso dela, é possível potencializar o diálogo entre outras áreas de conhecimento de forma a beneficiar o aluno leitor aprendiz de línguas estrangeiras, já que aquele leitor consegue ir além do processo de ensinoaprendizagem diferenciado. Do mesmo modo, Blay Peris (2017) destaca que, além do acercamento crítico à literatura e outras manifestações artísticas,

[...] a literatura comparada supõe [...] uma atitude diante da vida, da realidade e da sociedade. A diferença e a pluralidade são termos mais adequados para definir a realidade deste século. Desse modo, a experiência literária é concebida como um acontecimento dialógico no qual as vozes da história falam pela boca do autor, que é um emissor do seu próprio contexto histórico-cultural. (BLAY PERIS, 2017, p. 8 - tradução nossa)

Desse modo, de acordo com o pesquisador, incluir a literatura comparada nas aulas de ELE - Estudo de Língua Estrangeira - nos permite trabalhar, nesse ambiente, com os temas universais (amor, morte, etc.) comuns a todas as culturas. Blay Peris (2017) menciona ainda os benefícios de trazer outros aspectos culturais que, normalmente, não são tratados nas aulas de língua e literatura, como, por exemplo, a forma de se dirigir e de falar com um nativo, o espaço de aproximação física entre os falantes da outra cultura, os modos como expressar irritação ou humor, entre outros.

O leitor literário, ao entrar em contato com outras Literaturas e culturas, tem a oportunidade de tornar-se mais crítico e independente. Para tanto, é papel do profissional da prática docente, conforme aponta Fleck (2016), cumprir a grande missão 
de formar leitores que, por hábito e gosto, passarão a exercer uma leitura crítica, consciente e transformadora, seja no Ensino Fundamental ou no Ensino Médio.

Com relação a esse aspecto, embora se discuta muito sobre os reflexos e a importância da leitura e do ensino de Literatura na formação do leitor, percebemos, na prática educacional atual, a existência de muitos problemas, além de vários aspectos a serem considerados para análise, especialmente frente às novas tecnologias. No entanto, cabe ao professor, nesse contexto de mudança, atuar como mediador das leituras literárias, explorando o texto, discutindo sua compreensão e, a partir desta, promovendo uma interpretação crítica por meio das mais diversas abordagens.

Com as TIC, abrem-se novas possibilidades à educação, o que exige uma nova postura do educador. Diante disso, o desafio está em incorporá-las a partir dos conteúdos de ensino, sem esquecer, com isso, o entendimento e a competência que cada estudante tem sobre as tecnologias que a ele se apresentam. Somente assim ele poderá elaborar, desenvolver e avaliar práticas de ensino que promovam tanto o conhecimento quanto seus usos tecnológicos.

Segundo Arenaz (1995), o professor num ambiente com/na Internet é o elemento chave da mediação, e o aluno, protagonista de sua própria aprendizagem. Contudo, é papel do professor buscar estabelecer relações e analisar os mecanismos literários por meio de diferentes recursos pedagógicos, principalmente agora, nas salas de aula virtuais. Para tanto, novas abordagens e estratégias de ensino-aprendizagem devem ser pensadas a partir da grande rede mundial de comunicação: a Internet.

Cabe ressaltar que o uso da Internet no ensino somente atinge resultados significativos quando está integrado num contexto estrutural de mudança do processo de ensino-aprendizagem. É necessário que professores e alunos convivam com as novas tecnologias e estejam abertos para interagirem de forma efetiva. Devemos ter em mente que a Internet não modifica sozinha o processo de ensinar e de aprender, pois, dependendo da maneira como o docente a utiliza em sua prática pedagógica, esta pode atuar de forma a contribuir para a educação ou reforçar as formas tradicionais de ensino (Cf. MORAN, 1997).

O professor, nesse ambiente, não é mais o detentor do saber absoluto, centralizador do conhecimento e difusor deste. Ao contrário, ele deve incentivar o 
pensamento divergente, despertar a curiosidade dos alunos, atuar como facilitador da aprendizagem e trocar conhecimentos com os estudantes. Como afirma Moran,

\begin{abstract}
Ensinar utilizando a Internet pressupõe uma atitude do professor diferente da convencional. O professor não é o "informador", o que centraliza a informação. A informação está em inúmeros bancos de dados, em revistas, livros, textos, endereços de todo o mundo. O professor é o coordenador do processo, o responsável na sala de aula. Sua primeira tarefa é sensibilizar os alunos, motivá-los para a importância da matéria, mostrando entusiasmo, ligação da matéria com os interesses dos alunos, com a totalidade da habilitação escolhida. (MORAN, 1997, p. 149)
\end{abstract}

Como os alunos já têm incorporado culturalmente as mídias em suas comunicações cotidianas, cabe à escola mostrar a eles as possibilidades de uso educativo que esses meios possuem. Qualquer recurso digital usado pode dar resultados significativos quando está integrado a um contexto estrutural de mudança do processo de ensino-aprendizagem, no qual professores e alunos vivenciam formas de comunicação abertas, de participação interpessoal e grupal, efetivas.

O processo de ensino-aprendizagem depende mais da capacidade de comunicação do professor para estabelecer relações de confiança com seus alunos do que da própria tecnologia disponível (Cf. MORAN, 1997). A Internet não modifica, sozinha, o processo de ensinar e aprender, mas constitui mais uma mídia com diversos recursos que podem contribuir para a prática pedagógica dos docentes e a aprendizagem dos alunos, desde que haja planejamento e consciência na sua utilização.

Para chegar ao objetivo desse artigo, é fundamental um planejamento. Assim, propomos o seguinte percurso de trabalho: 2. Sobre El Lazarillo de Tormes (1554) momento em que o professor pesquisa sobre a obra a ser introduzida na aula, dessa forma, apresentamos uma breve análise dos recursos narrativos empregados ao longo da obra El Lazarillo de Tormes (1554) e seu contexto de produção, a fim de compreender alguns dos aspectos abordados no desenvolvimento das atividades subsequentes propostas com o uso das TIC; 3. Propostas - nossa produção de material didático a ser utilizado. Essas propostas estão pautadas em ações de mediação leitora que compreende três momentos essenciais de abordagem ao texto literário em sala de aula: atividades de pré-leituras, de leitura propriamente dita, de verificação de leitura e discussão e, finalmente, encaminhamentos à pós-leitura. Os materiais elaborados por nós, ou selecionados da internet, para essa proposta, estão disponíveis na seção de anexos. 


\section{SOBRE EL LAZARILLO DE TORMES (1554)}

El Lazarillo de Tormes (1554), considerado o texto fundamental espanhol, é de produção ibérica e da literatura universal que traz, entre outras características, a invenção do leitor moderno (Cf. GONZÁLEZ, 2010). Em seu entrecho, o leitor percebe, pela primeira vez na história da literatura universal e da cultura ocidental, que a voz narrativa deseja se mostrar íntima dele. Pode-se observar um diálogo familiar entre narrador e leitor estabelecido com o intuito de manipular um relato que mostre os acontecimentos a favor do narrador.

De acordo com González (2010), nessa narrativa renascentista percebem-se as contradições entre o afirmado pela voz narrativa e o mostrado nas entrelinhas do texto. Nessas contradições, o leitor é levado a decidir qual é o sentido da narrativa. Essa função, dentro dos processos de leitura que qualquer narrativa exige, é natural para nós, leitores de hoje, porém, é considerada, no contexto, uma inovação, o que a insere na lista das obras primas da literatura universal. Antes do Lazarillo, não acontecia essa interação entre narrador e leitor nas produções literárias.

Para explicar de outra forma, tomemos em conta o que era produzido na época: o Romance de Cavalaria. Se compararmos o processo de recepção de ambos, perceberemos que, enquanto o leitor destes romances simplesmente acreditava no narrado, na narrativa El Lazarillo é exigido dele que saiba refletir sobre esse narrador e sobre seu entendimento dos fatos apresentados.

Sevilla Arroyo (2009) aponta que o contexto de produção da obra é o início da decadência da Espanha Imperial, durante o reinado de Carlos V. Segundo Uribe (2012), a sociedade espanhola da época tinha pícaros como elemento comum da sociedade. A administração do império preocupava-se com gastos em guerras religiosas ao redor da Europa, não prestando atenção ao seu povo. Como resultado, o rico era extremamente rico, o nobre era nobre e o povo continuava a ser a grande massa miserável.

Depois da reconquista da península ibérica, a sociedade espanhola começou a fazer a distinção, antes inexistente, entre o cristão velho e o cristão novo, dando valor ao cristão "velho", aquele cidadão cuja família sempre foi cristã e não recém conversa. Como consequência disso, as populações judia e moura, que integravam os cristãos 
novos, situavam-se à margem. As sucessivas expulsões desses povos do território "espanhol” marcaram a história, sociedade e cultura ibéricas.

Em conformidade com isso, a honra não era compatível com a posse ou o exercício de um trabalho (ocupação de judeus no comércio e de árabes na agricultura). Não existindo outras possibilidades de comprovar a honra, a única forma era "viver das aparências". De acordo com Uribe (2012), o ditado espanhol "não somente você precisa ser, mas também tem que parecer" nasceu nesse contexto e era aplicado no cotidiano do grupo social acima referido.

Ainda que as riquezas e luxos fossem transportadas para a Europa em barcos carregados da América, os governantes espanhóis não tinham a intenção de investir no desenvolvimento do país. Como consequência, o pobre precisou encontrar saídas para sua sobrevivência. O trabalho, como destacado acima, não era bem visto. Sendo assim, como única alternativa, eles passaram a roubar e a enganar para forçarem uma falsa imagem de bom cidadão.

E, dessa forma, na narrativa da obra a ser lida, a personagem principal age e serve como espelho da sociedade da época. Ela não escolhe ser pícaro, já que nasceu sob tal sina, por ser órfão, além de ter um padrasto mouro. Essas características condenam a personagem à não adequação aos moldes característicos de um cristão velho, dentro do contexto da Espanha da primeira metade do século XVI.

Por conseguinte, a única forma de subsistir se encontra na abdicação da integridade, o que a leva a assumir o mundo das aparências (Cf. GONZÁLEZ, 2010) para poder aspirar à ascensão social. Devido a isso, e contra as expectativas que se esperam de um herói, a personagem aceita se casar com a amante do seu amo no último tratado; melhor dizendo, quando Lazarillo consegue fazer parte do estrato inferior da classe dominante, prefere silenciar sua própria capacidade crítica para permanecer no nível desejado (Cf. GONZÁLEZ, 2010). Nesse sentido, a personagem pícara é absorvida pelo universo corrompido da sociedade para fazer parte de um estrato social que ela considera razoável.

A análise do "Século de Ouro espanhol" (2012) pela pesquisadora Uribe aponta que o contexto social espanhol permite a produção da "novela picaresca". Como destaca Watt (2010), sobre as características das obras da tradição picaresca: “ao apresentar o comportamento humano, [...] certamente procura retratar todo tipo de experiência 
humana [...] seu realismo não está na espécie de vida apresentada, e sim na maneira como a apresenta" (WATT, 2010, p. 11). A reflexão sobre El Lazarillo de Tormes mostra-nos uma narrativa realista, ou seja, que não repete as formas do fazer literário anterior à sua escrita, que tematizavam a figura dos deuses, dos heróis, com um narrador onisciente que transfere um diálogo retórico.

Ao contrário disso, essa narrativa irrompe com a "realidade cotidiana trazida pelo narrador de primeira pessoa e exposta na forma de diálogo, [...] um diálogo familiar que faz parte do universo narrado" (GONZÁLEZ, 2005, p. 185). Assim, observamos na diegese da obra que o pícaro Lazarillo não critica a sociedade, mas sim apresenta, de forma realista, os fatos expressos no cotidiano do século XVI na Espanha imperial.

Além disso, segundo González (2010), essa obra seria um texto produzido sob o conceito do riso carnavalesco (BAKHTIN, 1999), pois o Lazarillo não consegue perceber, como personagem, a fronteira entre quem ri e quem são as pessoas que riem, já que essa possibilidade não existe. Em outras palavras, o autor anônimo escreve um texto carnavalesco mostrando um mundo às avessas: somente se consegue ser bom quem fingir possuir honra e bondade.

El Lazarillo de Tormes (1554) é a obra universal que influencia parte das produções literárias universais. Decidimos utilizar esse romance picaresco para mostrar possibilidades para se trabalhar, com a ajuda da Literatura Comparada, a leitura de textos literários na aula de línguas com a ajuda das TIC.

\section{PROPOSTAS}

Nessa seção, pretendemos mostrar formas de como abordar o conteúdo proposto com o texto Lazarillo de Tormes, numa versão que conta com a apresentação de Antonio García Ángel (ANÔNIMO, [1554] 2012), em formato PDF e disponível na internet (ver link nas referências). Com o intuito de aproveitar melhor o pouco tempo que dispomos de conexão com os alunos, optamos pela aplicação da modalidade de aula invertida, ou flipped classroom $^{1}$ (Cf. BENITO et al., s. d.). Dessa forma, a atividade de leitura será efetuada individualmente pelos alunos, mediante o estabelecimento de um mês de antecedência para a leitura programada. 
Porém, em um momento anterior a essa aula, será necessário que o docente faça uma apresentação da obra, iniciando pela contextualização. Para a exposição da narrativa, o docente poderá utilizar vídeos, slides, entre outros materiais nas mídias digitais. Reforçamos a necessidade de apresentar o texto literário para as turmas, no sentido de orientar os alunos a se envolverem na história, em cada uma das partes constantes na narrativa. Essa prática voltada à abordagem da cultura, de acordo com a leitura que faz Fleck das palavras de Montserrat Espinet (1999),

[...] é um dos aspectos mais úteis na motivação dos estudantes de língua estrangeira, já que esta promove o desenvolvimento integral, a consciência da existência de uma identidade cultural própria, ao mesmo tempo em que amplia a visão do "outro" - a alteridade. (FLECK, 2015, p. 169)

Em conformidade com a citação acima, conclui-se que os alunos deverão ser levados a compreender toda a contextualização histórica da época, a entender como estava estruturada a sociedade europeia naquele momento, e, com isso, é possível que eles absorvam muito mais a proposta da obra e sejam capazes não só de compreendê-la, mas também, de fazer inferências, comparações, análises muito bem elaboradas. Com esse intuito, destacamos alguns links que servirão de subsídio para o professor embasar sua explicação do contexto de produção da obra. Elaboramos um vídeo que pode servir para esse momento (ver "link 1" na seção de anexos).

Após esse momento de contextualização, elaboramos um formulário para $\mathrm{o}$ professor (igualmente, acessar o "link 2" na seção de anexos). Este contém um vídeo (ver "link" 3 na seção de anexos) selecionado da internet com o resumo do livro. Atrelado a esta atividade estão perguntas de compreensão auditiva das primeiras partes do vídeo. O professor pode também gravar um vídeo explicativo ou se valer de outro material que considere como mais conveniente. Nesse mesmo formulário, o aluno terá acesso a slides que trabalham com conteúdo voltado ao vocabulário utilizado na obra. $\mathrm{O}$ professor também pode optar por trabalhar, em uma seção separada, "palavras e frases chave" (ver "link 4" na seção de anexos). Esses dois primeiros momentos serão aplicados com o objetivo de potencializar o entendimento da obra em questão, já que se trata de uma produção medieval.

A narrativa consta de "7 tratados", ou capítulos. Depois da leitura de cada tratado, ou, agrupação de tratados - pois à exceção dos três primeiros, os quatro 
restantes são mais curtos - será utilizado um rápido quiz, via aplicativo Kahoot $^{2}$, com o propósito de assentar/verificar o entendimento das bases principais da narrativa (ver link 5 na seção de anexos). Antes de elaborar nosso próprio material, verificamos que o docente tem à sua disposição muitos Kahoots com o tema do Lazarillo de Tormes, porém, todos aqueles materiais foram criados para o leitor nativo e que valorizam a memorização. Algumas perguntas consideramos muito simples, outras, mal elaboradas porque não coincidiam com as respostas propostas pelo autor do Kahoot. Outras traziam descuidos quanto às regras gramaticais, inclusive algumas foram feitas com a variação linguística da Espanha, de forma tão específica, que o aluno brasileiro não entenderia, sem ser ensinado este aspecto com antecedência, ou pelo uso de gírias, ou pelas expressões idiomáticas.

O professor formador do leitor literário precisa de perguntas que instiguem a reflexão dos alunos. Portanto, decidimos elaborar o nosso próprio material que, além de verificar a grafia certa, foi planejado pensando nos alunos brasileiros e como forma de verificar aspectos essenciais da leitura. Desse modo, criamos cinco Kahoots: um para o tratado primeiro; um para o tratado segundo; um para os tratados quatro e cinco; um para os tratados seis e sete.

Como parte dos trabalhos, podemos incluir um mapa dos lugares da Espanha por onde, de acordo com o relato, passou a personagem Lazarillo (ver "link 6" na seção de anexos), incentivando o conhecimento desses lugares turísticos existentes na Espanha.

Após a realização da leitura da obra toda, em terceiro lugar, abrimos espaço para a audição da música de Mercedes Sosa e Calle 13, intitulada "Canción para un niño en la calle". O objetivo dessa atividade é de, inicialmente, trabalhar a parte de audição e de compreensão por meio da música. Expomos o endereço eletrônico do vídeo (ver "link 7"), e a atividade proposta em formulário do Google (ver "link 8"), na seção de anexos.

Após esse momento, iniciamos a discussão com a turma, na qual destacamos a comparação entre a obra El Lazarillo de Tormes e a música da audição, já que a literatura comparada não somente trata de uma aproximação crítica da literatura, mas, igualmente, supõe uma atitude crítica diante da nossa vida cotidiana. Assim, pretendemos que os alunos saibam fazer as leituras comparativas, de modo a apontar situações próximas, a observar as leituras diferentes sobre o mesmo tema no livro lido e na música apresentada. 
Enumeramos abaixo algumas perguntas que podem ser lançadas na discussão, caso haja a possibilidade de se levantar questões reflexivas: ¿En qué se diferencia el tema de la pobreza en el contexto de 1554 y en nuestra sociedad actual? ¿En qué aspectos nuestras sociedades son iguales o diferentes? ¿Las razones por las que Lazarillo roba son las mismas que las de un niño pobre hoy? ¿Un autor que escribe hoy una historia como la de Lazarillo, contextualizada en nuestra era, será que tendrá el mismo significado que el de 1554? ¿La historia de Lazarillo está escrita para reir o llorar? ¿La conciencia del Lazarillo hoy sería considerada normal? Para responder la pregunta, pensar en el personaje que escribe y cuenta su vida. ¿Qué es un pícaro? ¿Tenemos pícaros en la música de Mercedes Sosa y Calle 13?

Como atividade final, o professor poderia encorajar os alunos a elaborar um vídeo de resumo ou mesmo uma encenação de um trecho da obra. Ao propor este meio de tradução intersemiótica, o professor estaria estimulando seus alunos a inovação, a originalidade, a interpretação e a reflexão crítica, ao expressar a sua opinião sobre a leitura de El Lazarillo de Tormes. Propor a produção de um vídeo como atividade final de verificação de leitura possibilita engajar os alunos em uma metodologia ativa de aprendizagem. A criação de vídeos serve para fomentar não apenas a interpretação crítica da obra, mas para ampliar a criatividade e a capacidade comunicativa dos alunos.

\section{CONSIDERAÇÕES FINAIS}

Em linhas gerais, apresentamos neste artigo a possibilidade de emprego das tecnologias no ensino de Literatura nas aulas de ELE. Cabe ao professor a responsabilidade de dar continuidade às aulas. Portanto, é seu papel ressignificar os processos de construção do conhecimento, evitando uma abordagem tradicional, para, assim, conseguir desenvolver aulas mais interativas, lúdicas e colaborativas, de modo a envolver de forma efetiva os alunos que não tem outra alternativa que assistir aulas desde seus lares, dependendo da internet. Além do mais, o professor conseguirá dialogar com seus alunos na linguagem que eles conhecem/dominam mais do que os adultos: as tecnologias. Nesse contexto, com a proposta didática apresentada, compreendemos que as TIC auxiliam na constituição de espaços inovadores para uma série de possibilidades a nível educacional, promovendo o engajamento e a participação ativa dos alunos. 
Com respeito ao uso da literatura na aula de línguas, outras competências e estímulos da aprendizagem levarão ao aluno/jovem leitor aprendiz além de ampliar a compreensão do texto literário, já que esse tipo de práticas contribui para a formação de um leitor crítico. Sendo assim, a junção da Literatura à aula de língua espanhola e dos meios digitais, numa perspectiva crítico-reflexiva no âmbito da Literatura Comparada, facilita o desenvolvimento e a capacitação de leitores conscientes de sua realidade, impulsionando-os a agir e a transformar seu meio social.

Essa proposta para uma aula de língua espanhola como língua estrangeira, com atividades de aplicação da literatura comparada com ajuda das TIC, reitera que o processo de composição do material didático para o contexto digital exige de nós, professores, não apenas o conhecimento das tecnologias e dos meios digitais, mas também, abrange leituras críticas, teóricas, metodológicas, literárias, que precedem à seleção e à abordagem da literatura em sala de aula, seja ela virtual ou presencial.

Nesse contexto, produzir o material didático e mediar a leitura de obras literárias requer a mobilização de diversos conhecimentos e o uso de estratégias específicas, o que demanda interpretação, análise e seleção de recursos digitais que sejam expressivos no desenvolvimento das atividades. Em suma, fica explícito, ao observar cada etapa dessa proposta, que a pesquisa possui importante papel para o embasamento teórico necessário às práticas docentes.

\section{Referências}

ANÓNIMO. Lazarillo de Tormes. Bogotá: eLibros, 2012. Disponível em: https://www.unaula.edu.co/sites/default/files/ebooks/LazarilloDeTormes.pdf. Acesso em: 12 mai. 2020. (1554)

ARENAZ, Adalberto Ferrández. El formador en el espacio formativo de las redes. España: EDUTEC, 1995. Disponível em: https://ddd.uab.cat/pub/educar/0211819Xn20/0211819Xn20p43.pdf. Acesso em: 12 mai. 2020.

BAKHTIN, Mikhail. A cultura popular na Idade Média e no Renascimento: o contexto de François Rabelais. Tradução de Yara Frateschi. 4. ed. São Paulo-Brasília: Hucitec Editora da Universidade de Brasília, 1999. 
BENITO, María Teresa Villalba de; et al. (Orgs.). Flipped classroom en la práctica. s. 1.: ITStudy Education and Research Center, s. d.. Disponível em: http://flipit.hu/en/system/files/konyvek/flipit_book_es.pdf. Acesso em: 12 mai. 2020.

BLAY PERIS, Patricia. Sobre literaturas comparadas: una propuesta didáctica para la enseñanza del español. 2017. Disponível em:

http://repositori.uji.es/xmlui/bitstream/handle/10234/174296/TFM_2017_BlayPerisPatri cia.pdf?sequence $=1 \&$ isAllowed=y. Acesso em: 10 mai. 2020.

BRASIL. Orientações curriculares para o ensino médio. Linguagens, códigos e suas tecnologias. v. 1, Brasília: Ministério da Educação de Brasil-SEB, 2006.

CANDIDO, Antonio. O direito à Literatura. In: CANDIDO, Antonio. Vários escritos. 4. ed. reorg. pelo autor. São Paulo: Duas cidades, 2004.

FLECK, Gilmei Francisco. Tópicos de cultura en la enseñanza/aprendizaje de una lengua extranjera: caminos para la descolonización en América Latina. In: FIUZA, A. A. de F. A formação de professores de espanhol no âmbito do PARFOR: teorias, práticas e aprendizagens. Cascavel: UNIOESTE, pp. 79-92, 2015.

FLECK, Gilmei Francisco. Lectura y escritura: hábitos elitistas en América Latina desafíos para la escuela. In: FLECK, G. F. (org.) Parfor: una experiencia singular en la formación docente de lengua española y respectivas Literaturas. Porto Alegre:

Unioeste: Evangraf, pp. 47-76, 2016.

GONZÁLEZ, Mario Miguel. Lazarillo de Tormes: estudo crítico. In: ANÓNIMO. Lazarillo de Tormes. Tradução de Heloísa Costa Milton e Antonio R. Esteves. Revisão da tradução de Valeria de Marco. 1. ed. São Paulo: Ed. 34, 2005.

GONZÁLEZ, Mario Miguel. Lazarillo de Tormes. In: GONZÁLEZ, Mario Miguel.

Leituras de Literatura Espanhola: da idade média ao século XVII. São Paulo: FASESP, pp. 302-336, 2010.

MORAN, José Manuel. Como utilizar a Internet na educação. In: Ciência da Informação, vol.26, no 2, p. 146-153. Brasília. Maio/Agosto. 1997.

PEREIRA, Flávio. O ensino e a aprendizagem de Literaturas Hispânicas no contexto do PARFOR. In: FIUZA, Adriana Aparecida de Figueiredo. A formação de professores de espanhol no âmbito do PARFOR: teorias, práticas e aprendizagens. Cascavel:

UNIOESTE, pp. 79-92, 2015.

SANTAMARÍA, Laura. Acercamiento del español Americano a alumnos de ELE a través de algunos textos literarios. In: Nuevas perspectivas en la enseñanza del español como lengua extranjera II, pp. 647-654, 2000. Disponível em:

https://cvc.cervantes.es/ensenanza/biblioteca_ele/asele/pdf/10/10_0643.pdf. Acesso em: 18 ago. 2020. 
URIBE, Diana. El siglo de oro en la literatura española. Vídeo, 2012. Disponível em: https://www.youtube.com/watch?v=LPWu5kOdzGk. Acesso em: 09 mai. 2020.

WATT, Ian. A ascensão do romance: estudos sobre Defoe, Richardson e Fielding. Tradução de Hildegard Feist. São Paulo: Companhia das Letras, 2010.

\section{Anexos}

\section{MATERIAIS DA PROPOSTA APRESENTADA NO ARTIGO:}

Link 1: Vídeo, elaborado por nós, pensado no auxílio da contextualização da obra. O vídeo foi publicado em nosso canal: "Programa de Ensino de Literatura e Cultura" Disponível em: https://www.youtube.com/watch?v=y8GILbD1kEU\&t=18s. Acesso em: 29 mai. 2020.

Link 2: Formulário que ajuda a introduzir a aula. Disponível em: https://docs.google.com/forms/d/e/1FAIpQLSfRXviZmIRHPoLEGKO9GKHveTlJXXv VDxzjUNHluq4u3paMMw/viewform?usp=send_form. Acesso em: 12 mai. 2020.

Link 3: Igualmente, esse material que forma parte da introdução ao tema. É o mesmo vídeo do formulário no link anterior. Está aqui destacado, caso o professor preferir assistir diretamente ao vídeo (20 minutos) com seus alunos. O vídeo foi postado por Elena Llorente, no canal Elena emociones básicas, disponível em: https://youtu.be/9kafB38JQ08 . Acesso em: 12 mai. 2020.

Link 4: Com o intuito de trabalhar o vocabulário de palavras e frases presentes no Lazarillo, achamos mais conveniente empregar um material criado por Zilmarie95, em 2011. O atrativo desses flashcards é que também possuem a pronúncia das palavras. Disponível em: https://quizlet.com/4289652/flashcards. Acesso em: 12 mai. 2020.

Links 5: Consta de 5 quizzes na plataforma Kahoot, na ordem, organizados como um, dois, três, quatro e cinco, e, finalmente, seis e sete: https://create.kahoot.it/share/tratadoprimero/6f79fd66-24e0-462a-9c20-a22aae47fc79; https://create.kahoot.it/share/tratadosegundo/227082a6-8558-49a5-84ab-74faddb27787;

https://create.kahoot.it/share/tratado-tercero/7114acae-c7b5-4d5b-a0c1-b4e7f38c5d05; https://create.kahoot.it/share/tratado-cuarto-y-quinto/abf41ff9-15a0-4ef5-bd876307abf1346d; https://create.kahoot.it/share/tratados-sexto-y-septimo/be3680f4-01e9451e-bb4c-aaab1da70a4. Acesso em: 19 mai. 2020.

Link 6: Nesse mapa, o professor pode fazer uma viagem virtual pelos lugares da Espanha mencionados na obra. Material elaborado por Helena Fernández Figueras, publicado em 2019. Disponível em: https://prezi.com/p/ux1j4op83qn_/mapa-de-loslugares-donde-estuvo-lazarillo-de-tormes// . Acesso em: 12 mai. 2020.

Link 7: O vídeo de Calle 13 e Mercedes Sosa utilizado em nossa proposta está disponível em: https://www.youtube.com/watch?v=h0Bi01PqXTs. Acesso em: 13 mai. 2020. 
Link 8: O formulário elaborado a partir da música como atividade prévia à discussão comparativa pode ser acessado em: https://forms.gle/YzjnAAe6gJS4eS6w6. Acesso em: 19 mai. 2020.

\section{SUGESTÕES PARA AMPLIAR AS POSSIBILIDADES DA AULA:}

Sobre o Renascimento espanhol, sugerimos ao professor utilizar a página Blog de Mery Suárez Educ@ción: España en la edad moderna, como embasamento teórico para preparar sua aula. Disponível em:

http://www3.gobiernodecanarias.org/medusa/ecoblog/esuasan/espana-en-la-edadmoderna/. Acesso em: 12 mai. 2020.

Igualmente, os vídeos: La literatura española en el Renacimiento. Disponível em: https://vimeo.com/19887998. Acesso em: 12 mai. 2020; e El siglo de oro en la literatura española, de Diana Uribe. Disponível em: https://www.youtube.com/watch?v=LPWu5kOdzGk. Acesso em: 09 mai. 2020.

Para outra abordagem para a obra El Lazarillo de Tormes, sugerimos a página Juicio a Lázaro de Tormes: ¿Inocente o culpable?, na qual o professor terá acesso a detalhes importantes sobre a picaresca espanhola e, inclusive, com a proposta de atividades com alunos, mostrando como foi a atividade dos cursos de 2016 a 2017 e a unidade didática das atividades. A página pertence ao "Departamento de Lengua Castellana y Literatura" do Instituto IES Arrigorriaga, BHI. Disponível em https://sites.google.com/a/arrigorriagabhi.net/juicio-a-lazaro/-lazarillo-detormes/estructura-de-lazaro-de-tormes. Acesso em: 12 mai. 2020.

Do mesmo modo, pode ser trabalhada a leitura a partir do Gibi El Lazarillo de Tormes (ANÓNIMO). El Lazarillo de Tormes. Dibujos Chiqui de la Fuente. Guión Carlos R. Soria. Epílogo de R. García-Pelayo y Gross. México D. F.: Ediciones Larousse, s.d. Disponível em: https://app.box.com/s/kp4c7f0x5hk7qtmpoqjb. Acesso em: 09 mai. 2020.

Apontamos ainda as sugestões de músicas relacionadas a crianças em condição de rua. Disponível em: https://padlet.com/leilashai/uj1etn8inb4wks8k . Acesso em: 20 mai. 2020.

Recebido em: 29/05/2020

Aceito em: 15/08/2020

\footnotetext{
${ }^{1}$ Essa metodologia de ensino, flipped classroom, ou aula invertida, consiste em que: o estudo do conteúdo teórico é feito fora da aula "para desse modo utilizar o tempo de aula programado para as atividades práticas. [...] Ao mesmo tempo, no horário da aula, por meio de técnicas de aprendizagem ativa se desenvolve nos estudantes habilidades como a comunicação e colaboração, a resolução de problemas ou o pensamento crítico, todas elas habilidades mencionadas no século XXI" (BENITO et al., s.d., p. 3 tradução nossa). ${ }^{2}$ Para mais informações, visite: https://ferramentaseducativas.com/index.php/aplicacoes/online/112-
kahoot-ensina-conteudos-de-uma-forma-divertida-e-a-jogar. Acesso em: 23 mai. 2020.
} 